\title{
Parameters Affecting the Specific Energy Absorption of Circular Side Impact Beam
}

\author{
Sanjay D. Patil, Dheeraj S. Lengare, Arvind J. Bhosale, Kiran B. Bansode, \\ Rashtrapal B. Teltumade
}

\begin{abstract}
In vehicle design, safety of occupants is one of the most important criteria. During side collisions, space between vehicle body and occupants is very less as compared to frontal collision. Hence, scope for energy absorption due to deformation of vehicle body in side collisions is less. The strength of side door plays important role in the framework of vehicle side body. The strength of side doors during side collision depends upon the impact beam, vehicle construction, layout of doors etc. Among the mentioned parameters, strength of impact beam is a crucial parameter. The impact beam absorbs notable amount of impact energy by deforming during side collision. Design of side impact beam should be optimum as it is limited by weight of vehicle. Parameters like material, dimensions, shape and mountings of beam inside the door are affecting the strength of side impact beam. In this work parameters of circular cross-section impact beam like diameter of beam, thickness of beam and angle of mounting inside the door are studied. Finite element simulation of side impact beam is done in $A B A Q U S$ software and its relative effects on Specific Energy Absorption (SEA) capacity of beam is studied. The simulation results are validated with available literatures. The ANOVA analysis followed by Design of Experiments is used to determine contribution of each parameter on SEA. Further various parameters of circular impact beam are studied by examining the result analysis for crashworthiness of side door.
\end{abstract}

Keywords: Side impact beam; Side intrusion beam; vehicle side door; Taguchi method; ANOVA; crashworthiness of side door, Specific Energy Absorption

\section{INTRODUCTION}

Road accidents are major causes of premature deaths in India. It also leads to severe injuries, permanent disabilities and financial losses to the occupants. In 2018, India had 4, 67,044 road accidents. Out of total accidents 1, 51,417

Revised Manuscript Received on February 05, 2020.

* Correspondence Author

Sanjay D. Patil*, Autombile Engineering Department, Government College of Engineering and Research, Avasari (kh), Pune, India. Email: sanjaypatil365@gmail.com

Dheeraj S. Lengare, Autombile Engineering Department, Government College of Engineering and Research, Avasari (kh), Pune, India. Email: lengare27@gmail.com

Arvind J. Bhosale, Autombile Engineering Department, Government College of Engineering and Research, Avasari (kh), Pune, India. Email: pawandeep94@gmail.com

Kiran B. Bansode, Autombile Engineering Department, Government College of Engineering and Research, Avasari (kh), Pune, India. Email: kiran261282@gmail.com

Rashtrapal B. Teltumade, Autombile Engineering Department, Government College of Engineering and Research, Avasari (kh), Pune, India. Email: rashtrapal teltumade@rediffmail.com

(C) The Authors. Published by Blue Eyes Intelligence Engineering and Sciences Publication (BEIESP). This is an open access article under the CC BY-NC-ND license (http://creativecommons.org/licenses/by-nc-nd/4.0/) occupants were dead and 4, 69,418 were severely injured [1] The data also shockingly shows that in year 2018, in India per day 1279 road accidents occurred and 414 peoples died. Out of these total accidents, 58,774 accidents were side impact collisions and 15,477 people's had lost their lives [1]. This study also shows that in year 2018, average $10.2 \%$ lives are lost due to side impact collision. All this data shows that, the effects of side collision on vehicle design should be properly analyze. Generally in cars, active and passive safety systems are installed to protect the occupants. Active system technologies like traction control system, antilock-brake system etc. assists in prevention of collision. There are also passive systems like side air bag, seat belt, side impact beam etc. which prevent the occupants from severe injuries during collisions [2-3]. During side impact collisions, only side door is in between the occupant and the external object. Hence, the crashworthiness of car side door is crucial parameter during side impact collision. Crashworthiness is ability of the side door to absorb the impact energy during collision. Side impact beam also known as side intrusion beam, installed inside the side door is the key element in side door for crashworthiness [4-6]. During the side impact collision, the side impact beam gets deformed and it absorbs the impact energy of collision. As the Space between occupant and side door is less compared to the space between the frontal vehicle body, side impacts have the less scope for large deformations and leads in less amount of impact energy absorption [6-7]. Due to above concerns, proper study of design of an effective side impact beam is important. Currently vehicle sold in various countries around the globe are tested for various vehicle compliance like side crash safety, United state regulation Federal Motor Vehicle Safety Standards (FMVSS) No. 214, European Union regulation ECER95, China Regulation GB20071-2006 and Indian standards IS 12009-1996 etc. Homologation to the vehicles is given only after the vehicle successfully meets regulatory standards and specifications prescribed by the respective countries [8-11]. As per the Indian standards IS 12009, a long cylindrical or semi cylindrical rigid steel bar of $300 \mathrm{~mm}$ diameter is intruded along the circumferential surface on the side door from outside. The initial crush resistance, Intermediate crush resistance and peak crush resistances are measured at $150 \mathrm{~mm}, 300 \mathrm{~mm}$ and $450 \mathrm{~mm}$ of crush distance respectively. As per the standards, the initial crush resistance should not be less than $10 \mathrm{kN}$ or 0.6 times of kerb weight of vehicle, the Intermediate crush resistance should not be less than $20 \mathrm{kN}$ or 1.2 times of kerb weight of vehicle and peak crush resistances should not be less than $55 \mathrm{kN}$ or 2 times of kerb weight of vehicle $[10,12]$. 


\section{Parameters Affecting the Specific Energy Absorption of Circular Side Impact Beam}

The Indian standards IS 12009, hence experimentally approves the crashworthiness of the side door. From vehicle design point of view, weight is crucial parameter but for crashworthiness of side door, energy absorption by impact beam is important criteria. Hence an optimum design of side impact beam is required which will meet the IS 12009 standards and also the vehicle design aspects. So selection of optimum parameters for side impact beam becomes an important issue. The present work simulates the setup for the impact beam which is motivated from IS 12009 standard.

The crashworthiness of impact beam is evaluated by the Energy Absorption (EA), average crash force (Favg), Specific Energy Absorption (SEA), and Crash Force Efficiency (CFE) indicators [13-14], these parameters are used to perform comparative study of different impact beams having different materials, geometries, thickness, orientation inside the door etc. EA indicator is used to estimate the energy absorbing capacity of impact beam and it is equal to area under the force displacement curve of bending process. Higher value of EA indicates higher capability of beam to absorb the energy during collision. The mathematical relation for EA is,

$$
E A=\int_{0}^{\delta} F(x) d x
$$

Where $\mathrm{F}(\mathrm{x})$ is crash force, $\delta$ is deformation of beam. $\mathrm{F}_{\mathrm{avg}}$ is average value of crash force during whole bending process and can be calculated as followed,

$$
F_{a v g}=\frac{E A}{\delta}
$$

SEA indicator is used to indicate the energy absorb per unit mass of the impact beam. In vehicles, weight is a one of the most significant factor. Higher the value of SEA indicator indicates higher efficiency of the structure. The mathematical relation for SEA is, [14]

$$
S E A=\frac{E A}{\text { mass of beam }}
$$

The important parameters for analysis of bending process of side impact beam are geometry, material strength, thickness, beam orientation inside the door etc. [15]. In present work, a side impact beam of hollow circular cross-section is studied. The material of impact beam is kept same for all simulations due to weight and cost aspect of vehicle. SEA is crashworthiness indicator dealing with vehicle weight selected for further analysis of impact beam [13-15]. Aim of the present work is to analyze the effects of various parameters of circular impact beam on SEA indicators. The parameters considered in the work are thickness of hollow circular cross-section beam, diameter of beam and orientation of impact beam in side door. The FEA Analysis of the impact beam is performed in ABAQUS software. To validate the simulation results, parameters like material properties, dimensions and conditions are taken as reported in the literature [16]. The results obtained by current work simulations are compared with the literature results. To study effect of various impact beam parameters and to optimize the number of simulation, Design of Experiment (DoE) is performed as per Taguchi $\mathrm{L}_{9}$ orthogonal array, followed by ANOVA analysis.

\section{VALIDATION}

Before studying the various parameters affecting the crashworthiness indicators, validation of present simulation model is to be done with reported result in literature [16]. The simulation setup, material property and geometry are adopted from literature [16]. The simulation setup and geometry parameters are shown in Fig. 1 and Table I respectively, where, ' $\mathrm{D}$ ' is outer diameter of hollow circular beams, ' $\mathrm{T}$ ' is the thickness of beam, ' $\mathrm{L}$ ' is the length of beam, The beam is supported by cylindrical support of diameter R2 and span S. While the material property is tabulated in Table II.

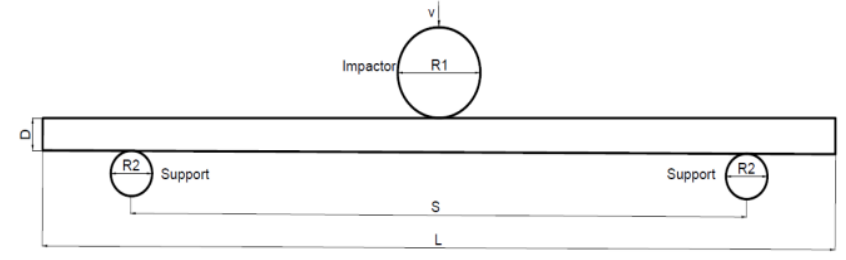

Fig. 1. Simulation setup

Table-I: Simulation and geometry parameters

\begin{tabular}{|c|c|c|c|c|c|c|c|}
\hline $\begin{array}{c}\mathbf{D} \\
(\mathbf{m m})\end{array}$ & $\begin{array}{c}\mathbf{T} \\
(\mathbf{m m})\end{array}$ & $\begin{array}{c}\mathbf{L} \\
(\mathbf{m m})\end{array}$ & $\begin{array}{c}\mathbf{S} \\
(\mathbf{m m})\end{array}$ & $\begin{array}{c}\mathbf{R 1} \\
(\mathbf{m m})\end{array}$ & $\begin{array}{c}\mathbf{R 2} \\
(\mathbf{m m})\end{array}$ & $\begin{array}{c}\mathbf{m} \\
(\mathbf{k g})\end{array}$ & $\begin{array}{c}\mathbf{v} \\
(\mathbf{m} / \mathbf{s})\end{array}$ \\
\hline 40 & 1.7 & 960 & 745 & 100 & 50 & 200 & 5.8 \\
\hline
\end{tabular}

Table-II: Material Properties

\begin{tabular}{|c|c|c|c|c|c|}
\hline Material & $\begin{array}{c}\text { Density } \\
\text { (kg/m3) }\end{array}$ & $\begin{array}{c}\text { Yield } \\
\text { stress } \\
\text { (MPa) }\end{array}$ & $\begin{array}{c}\text { Young's } \\
\text { modulus } \\
\text { (GPa) }\end{array}$ & $\begin{array}{c}\text { Poison's } \\
\text { ratio }\end{array}$ & $\begin{array}{c}\text { Tangent } \\
\text { modulus }\end{array}$ \\
\hline AISI1080 & 7860 & 869 & 205 & 0.28 & 5669 \\
\hline
\end{tabular}

A numerical model with explicit dynamic finite element is developed in ABAQUS software and studied by considering simulation and geometry parameters mentioned in Table I. A cylindrical impactor of diameter ' $\mathrm{R} 1$ ' and mass ' $\mathrm{m}$ ' is impacted circumferentially on the beam with initial velocity ' $v$ ' at mid span of the impact beam. There is negligible deformation in supports and cylindrical bars compared to impact bar so both are treated as rigid body in this work. Coefficient of friction of 0.3 is considered at all surface to surface contacts between impactor, beam and support. In ABAQUS software, 'All with self' surface friction pair is selected to avoid interpenetration of surfaces during beam bending. The mesh size of all elements is taken 1.5 and displacement of impactor is taken $200 \mathrm{~mm}$. The finite element model and deformed shape of beam are shown in Fig. 2 and Fig. 3 respectively.

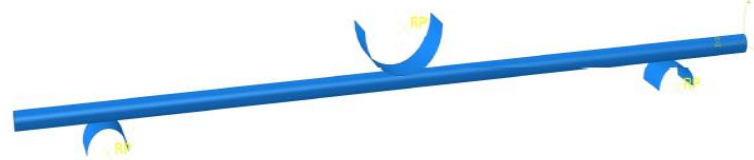

Fig. 2. Numerical model of simulation

Published By:

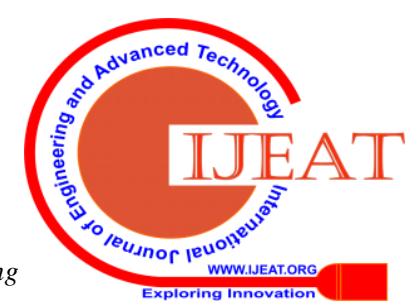




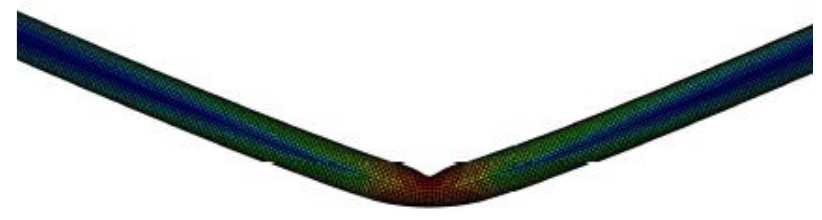

Fig. 3. Deformed shape of beam

From the force displacement diagram of simulation and by measuring the area under force displacement curve, energy absorption during the bending is calculated. $\mathrm{F}_{\mathrm{avg}}$ is calculated by using equation 2 and further SEA is calculated by equation 3. The results obtained from simulations are compared with reported literature results [16] and are shown is Fig. 4

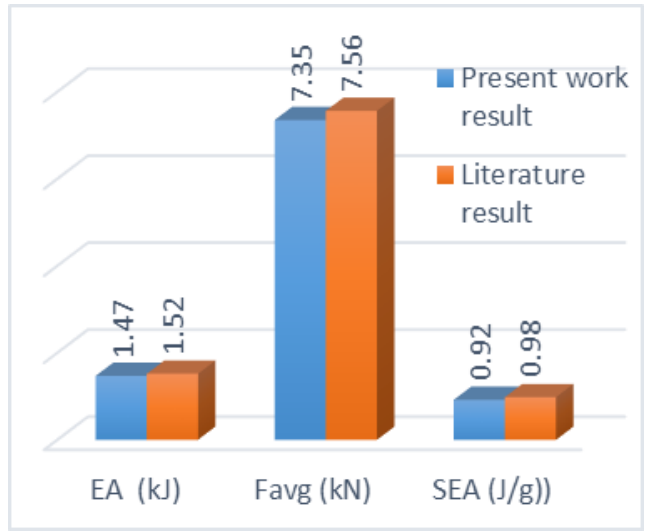

Fig.4. Comparison of results

\section{DESIGN OF EXPERIMENT FOR PARAMETER STUDY}

SEA of circular cross-section beam are affected by various parameters but by taking into account the material strength and manufacturing process, impact beam parameters like Diameter of beam, Thickness of beam, and Angle of orientation of beam in the side door are crucial $[12,15,16]$. Hence, this parameters are selected for further work of circular cross-section impact beam. To study the effect of said parameters on SEA, Design of Experiment methodology is used where diameter, thickness and orientation of beam are input parameters while SEA is the output parameters. As per the space availability consideration inside the side door, parameter levels are considered and it is presented in Table III. For every input parameters there are three number of levels.

Table-III. Parameters and their levels

\begin{tabular}{|c|c|c|c|c|}
\hline \multirow{2}{*}{$\begin{array}{l}\text { Sr. } \\
\text { No. }\end{array}$} & \multirow{2}{*}{ Circular beam parameter } & \multicolumn{3}{|c|}{ Parameters value at each } \\
& & $\mathbf{1}$ & $\mathbf{2}$ & $\mathbf{3}$ \\
\cline { 3 - 5 } & & 20 & 25 & 30 \\
\hline 1 & Diameter (mm) & 1.62 & 2 & 2.65 \\
\hline 2 & Thickness (mm) & 0 & 10 & 20 \\
\hline 3 & Angle of orientation (degree) & &
\end{tabular}

\section{A. Taguchi design of Experiment}

As per traditional approach of DoE, 'one variable at a time' is considered, but it requires large number of experiments and it is also time consuming. So, for robust design of experiments and to effectively reduce the number of experiments, Taguchi design of experiment methodology is used [17]. For three parameters and three levels of each parameter, Taguchi Lg orthogonal array is selected [18]. As per $L_{9}$ orthogonal arrays number of experiments are carried out by taking beam parameters and their levels mention in Table IV.

Table-VI. Parameters and their levels

\begin{tabular}{|c|c|c|c|}
\hline $\begin{array}{c}\text { Experiment } \\
\text { number }\end{array}$ & $\begin{array}{c}\text { Diameter } \\
\text { of beam }\end{array}$ & $\begin{array}{c}\text { Thickness of } \\
\text { beam }\end{array}$ & $\begin{array}{c}\text { Angle of } \\
\text { orientation }\end{array}$ \\
\hline 1 & 1 & 1 & 1 \\
\hline 2 & 1 & 2 & 2 \\
\hline 3 & 1 & 3 & 3 \\
\hline 4 & 2 & 1 & 2 \\
\hline 5 & 2 & 2 & 3 \\
\hline 6 & 2 & 3 & 1 \\
\hline 7 & 3 & 1 & 3 \\
\hline 8 & 3 & 2 & 2 \\
\hline 9 & 3 & 3 & 2 \\
\hline
\end{tabular}

The other parameters for simulation setup shown in Fig. 1 are kept same and are mentioned in Table I. Similarly, simulation procedure, elements size, friction between surface etc. are same as discussed in validation section. The displacement of impactor is taken $150 \mathrm{~mm}$ for all further simulation. TWIP steel is the most common material used for impact beam [19-20], hence TWIP 750/1000 material is taken in this work. The properties of material and the stress strain curves for loading conditions are adopted from the literature [20], and is mentioned accordingly in Table V.

Table-V. Properties of TWIP 750/1000 material

\begin{tabular}{|c|c|c|c|c|c|}
\hline $\begin{array}{c}\text { Name of } \\
\text { material }\end{array}$ & $\begin{array}{c}\text { Density } \\
\text { (kg/m3) }\end{array}$ & $\begin{array}{c}\text { Yield } \\
\text { stress } \\
\text { (MPa) }\end{array}$ & $\begin{array}{c}\text { Young's } \\
\text { modulus } \\
\text { E (GPa) }\end{array}$ & $\begin{array}{c}\text { Poison's } \\
\text { ratio }\end{array}$ & $\begin{array}{c}\text { Elongation at } \\
\text { break in } \\
\text { percentage }\end{array}$ \\
\hline $\begin{array}{c}\text { TWIP } \\
750 / 1000\end{array}$ & 8000 & 750 & 210 & 0.3 & 37 \\
\hline
\end{tabular}

The simulation experiments are performed by taking the level of parameters as mentioned in Table IV. Methodology used to evaluate the EA and SEA for all experiment are as discussed in validation section. Fig. 5 shows the graph of force versus displacement curve for all experiments and Fig. 6 (a), (b) and (c) shows the simulation results of EA and SEA respectively for all experiments.

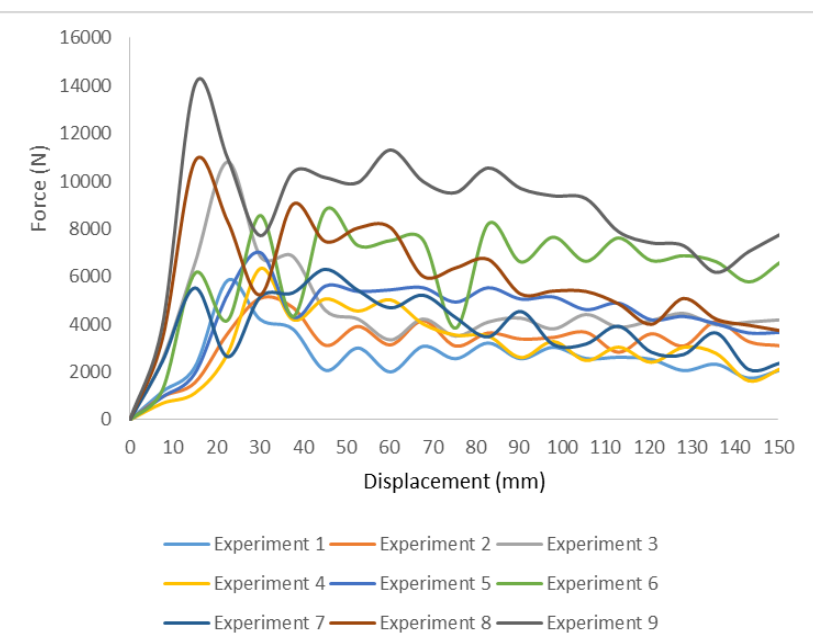

Fig.5. Force versus Displacement curves of experiments 
Parameters Affecting the Specific Energy Absorption of Circular Side Impact Beam

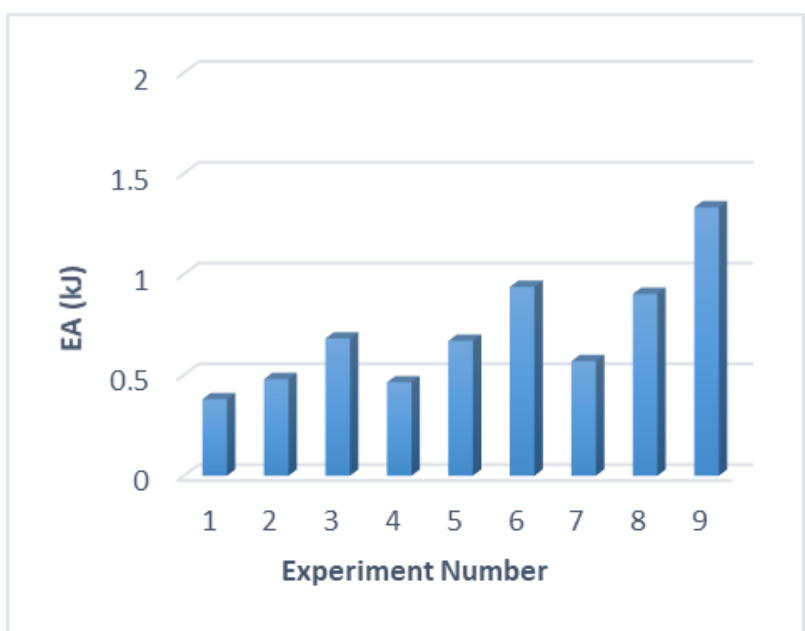

(a)

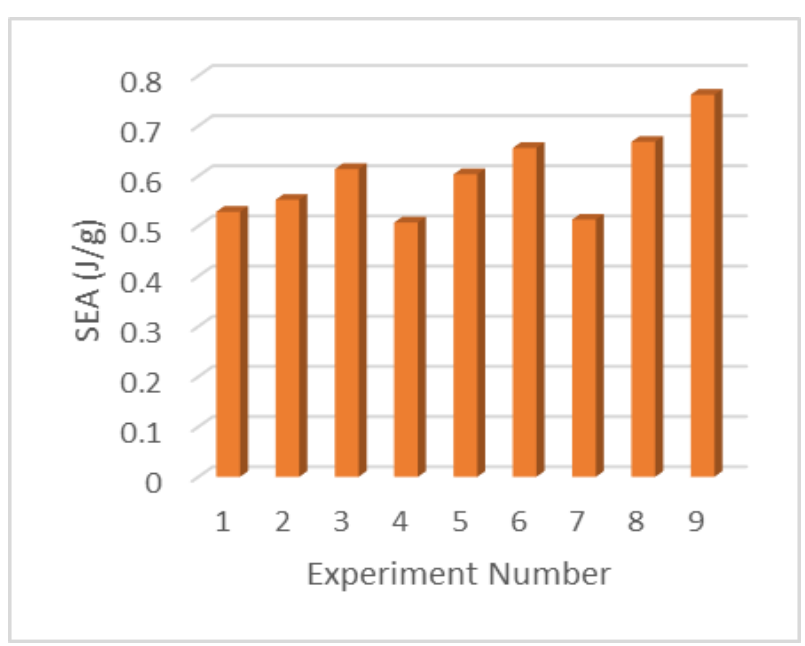

(b)

Fig. 6. Experiments results of (a) EA, (b) SEA

B. Contribution of Each Parameter on SEA

To understand the effect of each parameter on SEA, ANOVA analysis has been performed. The ANOVA analysis is used to investigate the process parameters which are significantly affecting on quality characteristics. As mentioned in earlier section for a higher crashworthiness, SEA value should be as large as possible. So, accordingly objective characteristics 'largest is better' type signal to noise ratio $(\mathrm{S} / \mathrm{N}$ ratio) is selected [22]. Equation 5 shows $\mathrm{S} / \mathrm{N}$ ratio of SEA, where, $\mathrm{i}$ is trial number and $n$ is total number of trials of each simulation. In the present work all simulations are carried out for one trial only hence, the value of $i$ and $n$ values is taken 1 . The $S / N$ ratio of all experiments is shown in Table VI.

$$
S / N=-10 \log \left(\frac{\Sigma y_{i}^{2}}{n}\right)
$$

Table-VI. S/N ratio of SEA

\begin{tabular}{|c|c|c|}
\hline $\begin{array}{c}\text { Experiment } \\
\text { No. }\end{array}$ & SEA (J/g) & S/N ratio \\
\hline 1 & 0.528 & -5.53948 \\
\hline 2 & 0.552 & -5.15591 \\
\hline 3 & 0.614 & -4.23991 \\
\hline 4 & 0.507 & -5.89557 \\
\hline 5 & 0.603 & -4.3918 \\
\hline 6 & 0.656 & -3.66492 \\
\hline
\end{tabular}

Percentage Contribution $=$

$\left(\frac{\text { veriation due to parameter }}{\text { total veriation }} \times 100\right)$

In order to calculate the percentage contribution of each parameter, total variance is calculated by equation 6 . Where $\mathrm{C}_{\mathrm{f}}$ is correction factor represented in equation 7 , which is the ratio of square of summation of $\mathrm{S} / \mathrm{N}$ ratio of all experiments and $n$ represents the total number of experiments that is 9 in current work.

$\mathrm{S}_{\mathrm{k}}$ is calculated from equation 8 where $\mathrm{m}_{\mathrm{i}}$ is total level of each parameter and $\mathrm{k}_{\mathrm{i}}$ is the value of each parameter taken from Table 7. 
Variances $\mathrm{V}$ is calculated from equation 9, where $\mathrm{m}-1$ is the degree of freedom (DoF) of each parameter that is 2 in present work. Error variances is zero in this work as all factors have equal number of level. So The Fisher's value (F) is same as variances value. The percentage contribution of each parameter is calculated by equation number 10 . All above mentioned calculations are tabulated in Table VIII

Table-VIII ANOVA analysis for SEA

\begin{tabular}{|l|l|l|l|l|l|l|}
\hline Parameters & $\mathbf{S}_{\mathbf{k}}$ & $\mathbf{D o F}$ & $\mathbf{V}$ & $\mathbf{F}$ & $\begin{array}{l}\text { Percent } \\
\text { contrib. }\end{array}$ & Rank \\
\hline Diameter & 1.872 & 2.0 & 0.936 & 0.936 & 17.702 & 2 \\
\hline Thickness & 8.202 & 2.0 & 4.101 & 4.101 & 77.569 & 1 \\
\hline $\begin{array}{l}\text { Angle of } \\
\text { orientation }\end{array}$ & 0.500 & 2.0 & 0.250 & 0.250 & 4.729 & 3 \\
\hline Error & 0 & & 0 & 0 & & \\
\hline Total & 10.574 & & 5.287 & 5.287 & 100 & \\
\hline
\end{tabular}

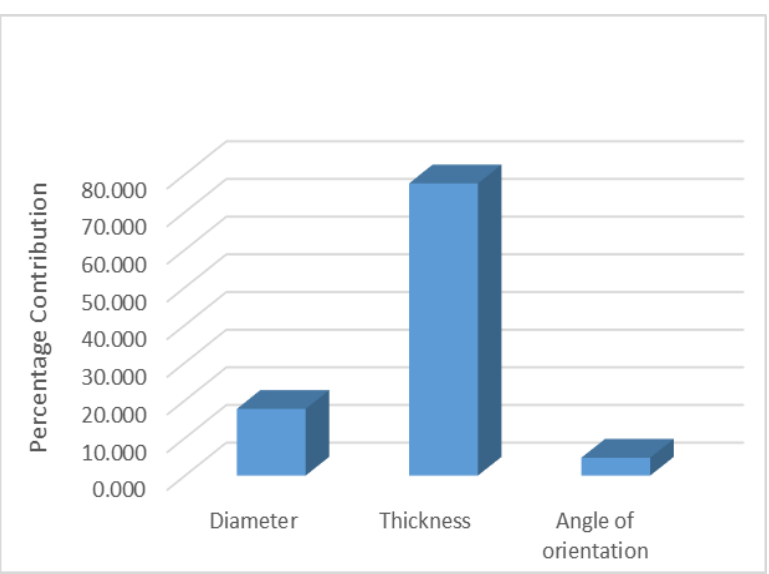

Fig.7. Contribution of impact beam parameters on SEA

From Table VIII it can be clearly seen that for hollow circular impact beam thickness has more effect on SEA indicator compared to other parameters. Fig. 7 show the graphical representation of impact beam parameters. Contribution of thickness on SEA is $77.569 \%$ and is maximum, followed by impact beam diameter and angle of orientation $17.702 \%$ and $4.729 \%$ respectively.

\section{EFFECT OF THICKNESS PARAMETER ON SEA}

As in previous session it is clear that in a circular cross section impact beam thickness parameters has shown more influence on SEA. Hence, the second part of the work deals with the study of thickness parameters of impact beam.

To determine the individual effect of thickness parameter on crashworthiness indicators, number of simulations are performed as per Table IX. The thickness parameter of impact beam is varied from level 1 to 3 and other parameters like diameter and angle orientation are kept constant in the simulations. The methodology used to evaluate the EA and SEA are same as discussed in previous section

Table-IX Simulations for thickness analysis

\begin{tabular}{|c|c|c|c|}
\hline \multirow{2}{*}{$\begin{array}{c}\text { Experiment } \\
\text { number }\end{array}$} & \multicolumn{3}{|c|}{ Parameters level } \\
\cline { 2 - 4 } & $\begin{array}{c}\text { Diameter } \\
(\mathbf{m m})\end{array}$ & $\begin{array}{c}\text { Thickness } \\
(\mathbf{m m})\end{array}$ & $\begin{array}{c}\text { Angle of orientation } \\
(\text { degree })\end{array}$ \\
\hline 1 & 1 & 1 & 1 \\
\hline 2 & 1 & 2 & 1 \\
\hline 3 & 1 & 3 & 1 \\
\hline
\end{tabular}

Fig. 8 shows the graph of Force versus Displacement curve for all experiments in Table 9. The simulation results of EA and SEA for all experiments are shown in Fig. 9 (a), and (b) respectively.

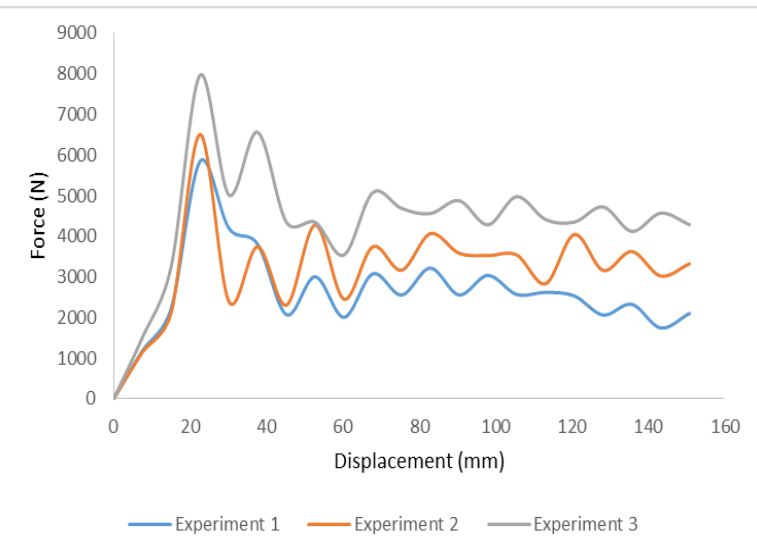

Fig. 8. Force versus Displacement curves of experiments for thickness analysis

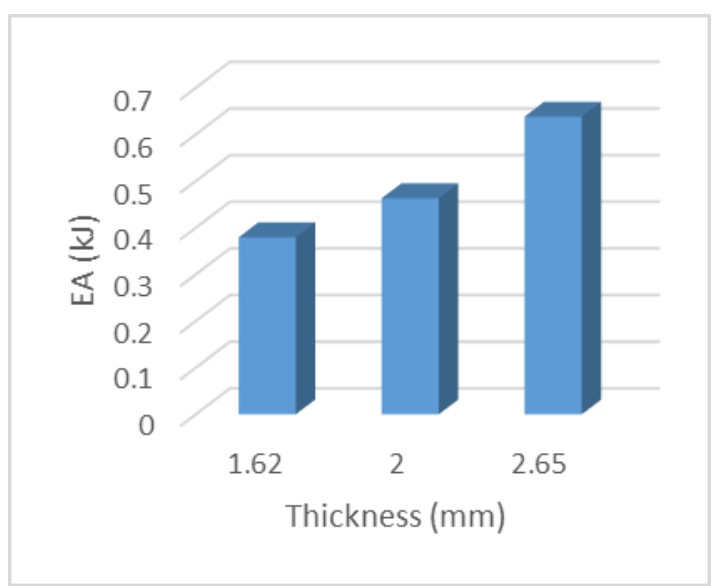

(a)

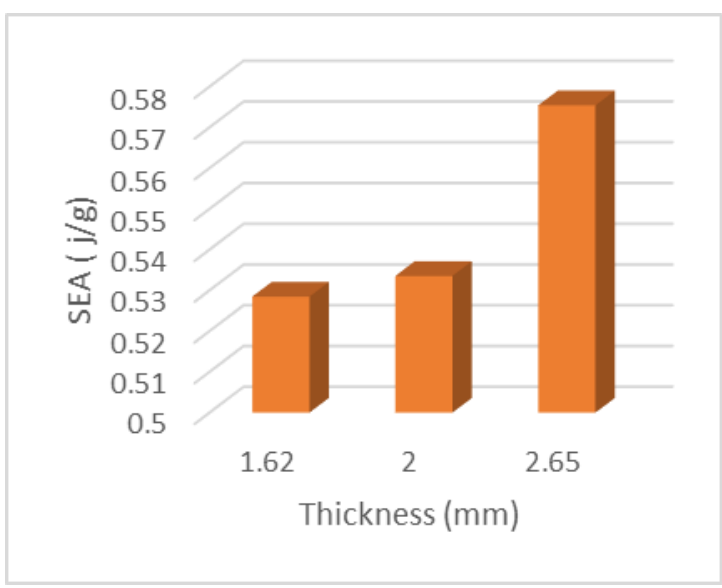

(b)

Fig. 9. Experiments results of thickness on (a) EA and (b) SEA

It can be clearly seen from Fig. 8 that, as the thickness of beam is increased, the crash force increases and it reaches maximum for $2.65 \mathrm{~mm}$ thickness. 


\section{Parameters Affecting the Specific Energy Absorption of Circular Side Impact Beam}

Greater thickness leads to greater cross-section area of the impact beam and henceforth it will give more strength to the impact beam to absorb more bending energy.

Fig. 8 also shows that the area under the force displacement curve increases as the thickness is increased from $1.62 \mathrm{~mm}$ to $2.65 \mathrm{~mm}$ and it leads to greater EA capacity of impact beam. Similarly Fig. 9 (b) shows that the SEA capacity increases with the increase in thickness from $1.62 \mathrm{~mm}$ to $2.65 \mathrm{~mm}$. As SEA indicator indicates energy absorption per unit mass, for same weight of different impact beams, the crashworthiness will be greater for that beam which is having more thickness.

\section{CONCLUSION}

In this work, thickness, diameter and angle of orientation parameters of hollow circular impact beam are studied for crashworthiness of impact beam. From DoE and ANOVA analysis percentage contribution of each parameter on SEA indicators are studied and it can be concluded that the thickness parameter of impact beam is clearly shows more effect of about $77.569 \%$ on SEA indicator

Present work also give light on the effect of individual parameters on SEA when other parameters are kept constant. The experiments performed clearly gives the effect of the diameter and thickness parameters on the crashworthiness. The crash force after reaching its threshold value, shows steadier responses as the thickness increases and the values of EA and SEA indicators increases. It can be also concluded that for same weight of different circular beams, those beam having higher thickness will have higher value of SEA.

\section{REFERENCES}

1. Road accident in India 2018 survey report, Ministry of road transports and Highways Transport Research wing. Available at https://morth.nic.in/road-accident-in-india

2. Michael Berlemanna, Andreas Matthes, "Science Direct Positive externalities from active car safety systems A new justification for car safety regulations", Journal of Policy Modeling 36 (2014) 313-329.

3. Javier Luzon-Narroa, Carlos Arregui-Dalmasesb, Luis M. Hernando, Emiliano Core, Alberto Narbona and Carlos Selgasg, "Innovative passive and active countermeasures for near side crash safety", International Journal of Crashworthiness, 2014 Vol. 19, No. 3, 209-221.

4. B. Watson, D.S. Cronin, "Side impact occupant response with varying positions", International Journal of Crashworthiness, Vol. 16, No. 5, October 2011, 569-582

5. C. R. Long, S. Chung Kim Yuena, G. N. Nuricka. “Analysis of a car door subjected to side pole impact" Latin American Journal of Solids and Structures, 2019, 16(8), e226.

6. Donata Gierczycka, Brock Watson and Duane Croni, "Investigation of occupant arm position and door properties on thorax kinematics in side impact crash scenarios comparison of ATD and human models", International Journal of Crashworthiness, 2015 Vol. 20, No. 3, 242-269

7. Yi Yang Tay, Chee Sern Lim, Hamid M. Lankarani, “A finite element analysis of high-energy absorption cellular materials in enhancing passive safety of road vehicles in side-impact accidents", International Journal of Crashworthiness, 2014 Vol. 19, No. 3, 288-300.

8. FMVSS 214, Side impact protection, NHTSA, USA, (2008). Available at http://www.crash-network.com/Regulations/FMVSS/fmvss.html.

9. EURONCAP, Pole side impact, (2013). Available at http://www.euroncap.com/Content-Web-Page/90769bbc-bb74-4129-a0 46-e586550c3ece/pole-sideimpact.aspx.

10. IS 12009-1996, Automotive vehicle safety requirement for side door of passenger cars-recommendation, Available https://archive.org/details/gov.in.is.12009.1995/page/n5/mode/2up

11. Semih Dagdeviren, Mecit Yavuz, M. Ozan Kocabas, Eren Unsal, Volkan Esat, "Structural crashworthiness analysis of a ladder frame chassis subjected to full frontal and pole side impacts", International Journal of Crashworthiness, 2016 vol. 21, no. 5, 477-493
12. Amit Pathak, Anish Kumar, and Rahul Lamba, "Effect of Beam Layout and Specification on Side Door Strength of Passenger Cars: An Experimental Approach to Analyze Its Effect and Contribution to Door Strength”, SAE Technical Paper , 2017-26-0023, 2017.

13. Ali Ghadianlou, Shahrir Bin Abdullah, "Crashworthiness design of vehicle side door beams under low-speed pole side impacts", Thin-Walled Structures, 67 (2013) 25-33.

14. Xiuzhe An, Yunkai Gao, JianguangFang, Guangyong Sun, Qing Li, "Crashworthiness design for foam-filled thin-walled structures with functionally lateral graded thickness sheets", Thin-Walled Structures, 91(2015)63-71

15. M. A. Shaharuzaman, S. M. Sapuan, M. R. Mansor, M. Y. M. Zuhri, "Passenger car's side door impact beam: A review", Journal of Engineering and Technology, Vol. 9 No. 1 Jan - June 2018.

16. TaoTang, Weigang Zhang ,HanfengYin, HanWang, "Crushing analysis of thin-walled beams with various section geometries under lateral impact", Thin-Walled Structures, 102(2016)43-57

17. Mohammad VahabMousavi, HadiKhoramishad, "The effect of hybridization on high-velocity impact response of carbon fiber-reinforced polymer composites using finite element modeling, Taguchi method and artificial neural network", Aerospace Science and Technology 94(2019) 105393.

18. Shakil A. Kagzi, Sanjay Patil, Harit K. Raval, "Factors Affecting Weld Line Movement in Tailor Welded Blank", International Journal of Industrial and Manufacturing Engineering, Vol:8, No:6, 2014.

19. Jean-HubertSchmitt, Thierry Iung, "New developments of advanced high-strength steels for automotive applications", C. R.Physique, 19(2018) 641-656

20. Advanced High-Strength Steels Application Guidelines, world auto steel, Version 6.0, April 2017.

21. L.M. Moore, M.D. McKay, K.S. Campbell, "Combined array experiment design”, Reliability Engineering and System Safety, 91 (2006) 1281-1289.

22. Puneet Sharma, Amitabh Verma, R.K. Sidhu, O.P. Pandey, "Process parameter selection for strontium ferrite sintered magnets using Taguchi L9 orthogonal design" Journal of Materials Processing Technology, 168 (2005) 147-151.

23. Ilhan Asiltürk, Harun Akkus, "Determining the effect of cutting parameters on surface roughness in hard turning using the Taguchi method", Measurement, 44 (2011) 1697-1704.

\section{AUTHORS PROFILE}

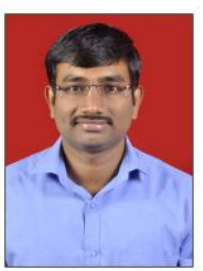

Sanjay D. Patil, earned his Masters in Technology in CAD/CAM Engineering from SVNIT, Surat (IN). He is having 5 years of industrial experience in piping design at L\&T, Mumbai and has 4 years of teaching experience in engineering college. He is currently working as Assistant Professor in Automobile Engineering Department of Government College of Engineering \& Research, Awasari Khurd, Pune(IN). His Research Interest: FEA, Non-linear Analysis, Impact Analysis, Optimization Technology, Meta Forming and MATLAB Coding.

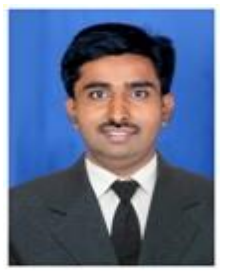

Dheeraj S. Lengare, earned his Masters in Technology in Machine Design Engineering from Walchand College of Engineering, Sangli (IN). He is having 1 years of industrial experience in design department and has 6 years of teaching experience in engineering college. He is currently working as Assistant Professor in Automobile Engineering Department of Government College of Engineering \& Research, Awasari Khurd, Pune (IN). His Research Interest: FE Analysis, Multi Body Dynamics, Engine Design, Kinematics of Machines, Vehicle Dynamics, Vibration Analysis, Gear Technology.

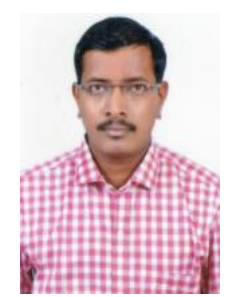

Arvind J. Bhosale, earned his Masters in Technology in Automotive Engineering from VIT University, Vellore. (IN). He is having has 6 years of teaching experience in engineering college. He is currently working as Assistant Professor in Automobile Engineering Department of Government College of Engineering \& Research, Awasari Khurd, Pune(IN). His Research Interest: Cylinder Bore Deformation, Piston Coating, Vehicle Structures and Systems.

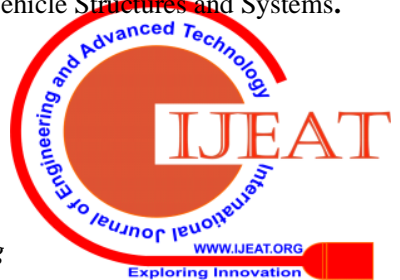




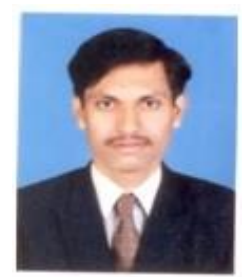

Kiran B. Bansode, earned his Masters in Technology in Design Engineering from College of Engineering Pune, (IN). He is having has 11 years of teaching experience in engineering college. He is currently working as Assistant Professor in Automobile Engineering Department of Government College of Engineering \& Research, Awasari Khurd, Pune(IN). His Research Interest are: FEA, Composite Materials and Biomedical Instruments.

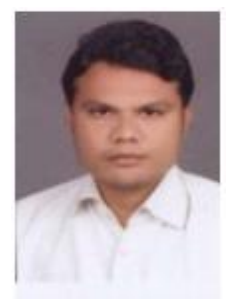

Rashtrapal B. Teltumade, earned his Masters in Technology in CAD/CAM Engineering from RTM University, Nagpur(IN). He is having has 7 years of teaching experience in engineering college. He is currently working as Assistant Professor in Automobile Engineering Department of Government College of Engineering \& Research, Awasari Khurd, Pune(IN). His Research Interest are: FEA, CAM, CNC Programing and Manufaturing Technology. 